\title{
Fostering the Scholarship of Teaching and Learning: Communities of Practice
}

\author{
Barbara L. Cambridge \\ American Association for Higher Education
}

As part of the scholarship of teaching and learning, faculty members study the ways in which they teach and students learn in their disciplines, and how campuses foster this scholarship at an institutional level. A national initiative called the Carnegie Academy for the Scholarship of Teaching and Learning constitutes three programs to engage and support individuals, campuses, and disciplinary associations in this form of scholarly work. In To Improve the Academy (Volume 18) this program was discussed. The article this year offers examples of individual faculty and campus initiatives centered on the scholarship of teaching and learning.

\section{INTRODUCTION}

ennis Jacobs has introduced cooperative learning into a large lecture course of general chemistry at the University of Notre Dame. The retention rates, test performance, and interest level of students in the cooperative learning course have exceeded those for students of similar ability enrolled in a more traditional general chemistry course on the same campus. Dennis is interested now in answers to the following questions: 1) Which features of the new course (pairing students in lecture to analyze and predict chemical behavior, small group problem solving activities, weekly graded homework, online quizzes, increased socialization) have had the greatest impact on student learning? 2) What design elements of cooperative learning activities are most successful in stimulating meaningful discussion, promoting deeper conceptual understanding, and developing individual problem solving skills? and 3) What is the 
long-term impact of such a course? Are students more successful in advanced courses if they have had a collaborative problem solving experience in a foundation course?

Like Dennis, most faculty have questions about the impact of their pedagogical decisions on student learning. And more and more faculty are doing something about finding answers to those questions through designing projects that build on what is known about learning, specifically about learning in their disciplines. This exciting work occurs in pockets on campuses of all kinds throughout the country, but often it remains local, improving teaching and learning within the investigator's own classroom but not adding to the knowledge base of the discipline, partly because of traditions about teaching that thwart its identification as scholarly work. Teaching has been regarded as private, difficult to study and critique, and less worthy than traditional research of serious regard and valuing.

Fortunately, faculty who pose, study, and begin to answer intriguing questions about their teaching can enter a newly emerging community of scholars. These scholars apply to their scholarship of teaching criteria pertinent to all scholarship: clear goals, adequate preparation, appropriate methods, significant results, effective presentation, and reflective critique (Glassick, Huber, \& Maeroff, 1997). They expect to go public with their findings, to receive the kind of peer review that interrogates their methods and conclusions, and to change their teaching and scholarly investigations of teaching based on that review. They also expect that their institution's reward system will acknowledge and value their scholarship of teaching and learning.

You may be asking at this point what planet I am writing about. But I did say "an emerging community of scholars." Communities must be built, and there are multiple individuals and groups committed to the building of this new community of scholars of teaching and learning. In this chapter, I will describe one effort to enlarge this new community through support of individuals, campuses, and associations devoted to the work. Dennis is a member of that effort, and you with your campus are welcome to join this growing community.

\section{The Carnegie Academy for the Scholarship of Teaching and LEARNING}

The Carnegie Academy for the Scholarship of Teaching and Learning (CASTL), with funding from The Pew Charitable Trusts and in collaboration with the American Association for Higher Education, is designed to foster the practice of scholarly inquiry about teaching and learning. Its three parts attend to three ways in which faculty members enter their pro- 
fessional worlds: as individuals, as members of a campus faculty, and as members of disciplinary groups.

\section{Pew Scholar Fellowship Program}

The Pew Scholar Fellowship Program selects scholars from designated disciplines to pursue their work in a concentrated way through funding, opportunities for interactions with other scholars, and, all importantly, time for carrying out a scholarly project.

Pew Scholars are contributing to the emergent definition of the scholarship of teaching and learning. Pat Hutchings, senior scholar at the Carnegie Foundation for the Advancement of Teaching and leader of its CASTL higher education work, suggests that the definition can begin with what the scholarship of teaching and learning is not.

1) The scholarship of teaching and learning is not new. Faculty members have generated important work-from many academic levels and disciplines-for many years upon which new scholars can build. Traditionally, however, faculty members have not become familiar with this literature through their graduate programs.

2) The scholarship of teaching is not for everyone for all time. Faculty members do different kinds of scholarly inquiry and pose different questions at different times in their professional lives. Some scholars will choose to focus on teaching and learning; others will not. Some will choose to do this work throughout their careers; others may move in and out of the work.

3) The scholarship of teaching and learning does not replace other kinds of scholarship. The scholarships of discovery, application, and integration join with the scholarship of teaching as one way to look at an array of scholarly possibilities.

4) Each discipline offers different ways to approach this work. For example, rhetoric and composition warrant narrative as a way to investigate and disseminate learning; chemistry values a more empirical approach.

5) The scholarship of teaching and learning is not aimed exclusively at publication. Scholars of teaching and learning are exploring multiple ways of making their work public, including the web, faculty development activities, and public presentations.

6) The scholarship of teaching is not simply for a faculty member's own improvement. It contributes to the practice of others.

7) No one has this kind of work all figured out (Hutchings, 1999). 
In fact, the work of helping to figure it out is one challenge for Pew Scholars. Ansel Adams once said that there is nothing worse than a clear image of a fuzzy concept. Knowing that a definitive definition would be premature at this time, the Pew Scholars will over time increase knowledge about the concept of the scholarship of teaching and learning. The kinds of projects contributing to this development are as various as the scholars doing them. Here is just a glimpse of the range of work undertaken:

- In business, Anthony Catanach, accounting at Villanova University, is developing strategies for long-term assessment of students' use of competencies from his intermediate financial accounting course, a two-semester course considered the core of the accountancy major. He wants to determine the effects of innovative pedagogies used in his course on students' performance in subsequent classes and professional work.

- In English, Mariolina Salvatori, the University of Pittsburgh, is theorizing an approach to teaching that develops a teacher's attentiveness to her students" "moments of difficulty" for their hidden potential to produce understanding. Naming something "difficult" demonstrates a form of knowledge that is both profitable and responsible to tap. She is studying the stumbling blocks in learning in different disciplines to understand how other disciplines confront this aspect of teaching.

- T. Mills Kelly, in history at Texas Tech University, is focusing on the ways in which student learning changes in response to the medium used to present essential source materials. Running parallel sections of the same Western Civilization course offering materials in multimedia format and in print only, he is particularly interested in the influence of the web.

- Peter Alexander's "Math and Social Justice" capstone course for undergraduate mathematicians at Heritage College has the key goal of enhancing students' quantitative worldview while they work on projects that meet each student's definition of social justice and which benefit local communities. Beginning from Dubinsksy et al.'s Action, Process, Object, Schema model of undergraduates' mathematics understanding, Peter is developing ways to assess students' growth in quantitative worldview.

- Stephen Chew, a psychologist at Samford University, is examining 
the effect of surface and structural components of examples used by teachers. Teachers often give surface components, which strongly influence student understanding and ability to generalize from the example. Stephen aims to help faculty in multiple disciplines structure examples and problems to optimize student understanding.

- As editor of Teaching Sociology, Jeffrey Chin of Le Moyne College is studying the evolution of the scholarship of teaching in sociology from 1983-1998, using papers published in the journal as a database. He will compare his results with a 1983 study that extended back to 1973 to determine if progress has been made in cumulative scholarship and in a convergence of teaching-learning strategies.

- Deborah Vess, at Georgia College and State University, is examining the effects of interactive, online modules in an interdisciplinary global issues course by developing an assessment instrument to determine the development of students' critical abilities in the modules and interviewing students to ascertain intellectual problems faced in constructing their solutions and integrating resources. She wants to understand how students apply abstract theory to actual world situations and to document the relationship of interdisciplinary work to growth in critical abilities.

This sample of the range of projects illustrates the interesting intellectual problems that are challenging scholars in multiple fields. The Pew Scholars Fellowship Program promotes synergy among these scholars.

\section{Campus Program}

The second component of CASTL also offers synergy, this time among campuses. The Campus Program is designed for institutions of all types that are prepared to make a public commitment to new models of teaching as scholarly work and is implemented through the American Association for Higher Education. Any interested campus is encouraged to organize its efforts and then to register its process and goals so that all campuses can learn from one another.

\section{Developing a Discourse}

Whenever a new community of scholars forms, the community develops language that it collectively uses to talk about what it wants to talk about. Because the term "scholarship of teaching" is so new, the Campus Program begins with a campus-wide focus on a draft definition of the 
scholarship of teaching, and is offered as a conversation starter. In fact, the first phase of Campus Program participation is named "campus conversations" to emphasize the need for dialogue and for developing discourse about teaching and learning. Campuses are invited to take apart and revise the draft definition so that the campus has a clearer sense of what it means by doing the scholarship of teaching and learning. The draft definition is, "The scholarship of teaching is problem posing about an issue of teaching or learning, study of the problem through methods appropriate to the disciplinary epistemologies, application of results to practice, communication of results, self-reflection, and peer review."

Several campuses have reported their negotiated versions of a definition. These examples illustrate the thinking at three quite different campuses, two of which have generated a definition and one of which has a process in motion that suits the size and type of campus that it is.

\section{Abilene Christian University}

Following a series of departmental and college meetings and discussion on an interactive web page, Abilene Christian University decided on major changes in the definition because they feared that the language emphasized a research methodology that would exclude some practices such as curriculum revision or teaching portfolios that they believed are appropriately classified as scholarship of teaching and that the language of the draft definition emphasized the process more than the definition. Their definition reads, "The scholarship of teaching is public discourse conceptualizing teaching." "Public" is making our work accessible to others for critical review and use. "Discourse" includes oral and written discourse in such varied contexts as curriculum committees; faculty development presentations; and publications on the web, teaching portfolios, or journal articles. While both informal and formal opportunities to present findings are considered scholarship of teaching, they are weighted differently in faculty evaluations such as tenure and promotion. "Conceptualizing" teaching is more than good teaching: It requires careful thought, analysis, and self-reflection about teaching. "Teaching" cultivates the exchange of ideas among teachers, students, and others in and out of the classroom.

\section{Elon College}

Elon College frames a different definition:

The scholarship of learning/teaching a) seeks to develop new knowledge (through discovery, integration, application) in the 
field of inquiry and to share what is learned widely so that insights can be built upon and oversights corrected; $b$ ) invites collaboration throughout the process; $c$ ) sets a direction of inquiry and commits to shared standards as to how results will be measured; d) remains alert to the most exciting thinking in the disciplines that bear on the task; e) invites constructive critique from the academic community (colleagues, students, and like-minded peers).

We choose to speak of the learning-teaching enterprise. This shift emphasizes that what is examined must be a partnership of students and teachers in which both partners learn and both partners, in different ways, teach. We wanted to make learning central and also to highlight educational content in the various fields.

\section{The Ohio State University}

To root the discussion in concrete, disciplinary contexts, each member of the executive council of the Academy of Teaching convened a conversation in her or his own academic unit (involving similar units if desired). The proposed topic for discussion was "Learning Pitfalls in Introductory Classes." The conversations addressed such questions as: What are some common concepts that are especially confusing for students in our introductory courses? What skills are especially hard for them to master? How do we know when students are really stuck? How do we explore the nature of the problem? What do we do with the information we obtain? Are there systematic ways in which our faculty and discipline could address these issues and share our findings? Based on the answers to these questions, how do we define the scholarship of teaching for our context? Is this definition applicable to nonintroductory courses as well?

A forum is now planned at which different groups will compare their results and look for commonalties across disciplines. The goal is to arrive at a university definition of the scholarship of teaching, identification of the ways in which it is supported and constrained, and a plan of action for cultivating such scholarship in the future.

\section{Identifying Conditions for Doing THe Scholarship of Teaching AND Learning}

In the next part of campus conversations, campuses identify ways in which they support or inhibit the scholarship of teaching and learning. Campus groups take up such questions as who does the scholarship of teaching and learning on our campus? Do hiring and orienting practices 
locate and support faculty members committed to the scholarship of teaching? What are the most central teaching issues on our campus, and how is the campus addressing those issues? Are faculty members rewarded for doing the scholarship of teaching? How does our campus culture discourage, and how does our campus culture affirm the scholarship of teaching and learning? What specific steps can the campus take to create conditions generative of the scholarship of teaching and learning? This environmental scan enables a campus to identify an area for study and actions that will enhance its support for this kind of work.

Campuses that have completed their campus audit and have determined or are deciding on a focus for future campus-wide work are inevitably considering a range of work. Several examples signal that range.

\section{Western Washington University}

Western Washington University has drafted an action plan to profile the scholarship of teaching and learning in a way that elevates the status of teaching on its campus. With commitment from its president, who provided a summer stipend for a faculty leader to work with colleagues for planning, the campus will focus on a theme during each of three quarters of the academic year: recognizing the scholarship of teaching, reflecting on that work, and rewarding it. These 3-R's discussions will begin first term with main events such as a presidential luncheon for all faculty and a series of campus lectures and breakfast meetings followed by workshops.

In addition, 35 faculty members from each of the campus's 35 departments and programs are being selected to examine the effectiveness of a case study and peer review model to develop and advance faculty skills intended to enhance student learning in critical thinking, writing in the disciplines, symbolic reasoning, and affective development. They will try to answer the following questions: Can a faculty-based case study grounded in a peer review and self-reflective approach improve student learning in noncontent domains? Will this process significantly improve instructional competence and cross-disciplinary dialogues about teaching and learning and enhance the scholarship of teaching at WW'U? Faculty will generate case studies from their own teaching as exemplars of student learning problems and themes in noncontent domain. These case studies will be used as springboards for faculty using a variety of methodologies. The campus plans to use electronic threaded discussions, inclassroom peer review, self-reflective writing, and the identification and development of student learning and faculty development assessment tools. 


\section{Augustana College}

Augustana College faculty have identified five general areas on which they would like to focus. The participating faculty (45 of the college's 150 full-time faculty members) have affiliated themselves with one of five question groups. The five groups and some of the questions under consideration include:

The student. How can an instructor tap students' internal motivation? How do various modes of learning and teaching interact with differing styles and abilities? Is students' motivation subject to change through strategies we can employ?

The classroom. What is the interaction between content and teaching strategy? How do gestures facilitate learning? How can teaching techniques be matched to outcomes and audience?

The engaging text. What happens to students when they are assigned readings? What happens during highlighting? Is there a difference in reading comprehension from hard copy versus screen text? Can we teach students to "talk back" to textbooks? What prereading approaches facilitate the reading process?

Impact of tecbnology. How does technology impact learning? Do course webpages and chat groups facilitate learning? Does requiring that writing assignments be on disk improve the quality of writing and feedback?

Foreign study. How does foreign study impact students? What intellectual and social growth occurs during these experiences? What classroom experiences best facilitate learning in this context?

Resident campus experts on quantitative and qualitative research approaches have met with the participants to discuss options for structuring the inquires. Members of each group read common texts to provide a starting point for refining their research questions. By the end of summer 1999, each group will have developed a strategy for investigating a specific question.

\section{Rockhurst College}

The two central questions for Rockhurst College are 1) How do we make our inquiries about teaching and learning issues public in ways useful to our campus colleagues and to our disciplines? and 2) Can we make this new area of scholarly discussion highly interdisciplinary to promote wider dialogue and new perspectives?

A seminar group of 15 faculty from a variety of disciplines and levels of teaching experience will follow four steps in this process. Along the 
way each seminar member will have access to an on-campus consultant-a faculty or administrative volunteer from a different discipline that has special expertise (teaching and research). These consultants will provide suggestions on resources and methods, serve as sounding boards for ideas, and occasionally join seminar discussions or make special presentations. Thus the "broadcast area" and potential impact of the seminar will be immediately increased. The action plan for the seminar includes four steps:

Step 1) To develop a common language, seminar members will read a core set of materials on learning theory, the scholarship of teaching and learning, college teaching, assessment, and higher education. Each seminar member will select a course they teach to serve as a practical context for exercises and discussions related to teaching as a scholarly act.

Step 2) Each seminar member will "deconstruct" the course they have selected-reexamining its component parts (objectives, assignments, assessments) in light of the readings, discussions, seminar presentations, and advice from consultants. The primary goal will be to identify discipline-based and interdisciplinary areas of research within a course framework. Participants will present their findings to the seminar for further discussion and refinement. They will also engage in scholarly projects suggested by this process.

Step 3) Building on Step 2, the seminar will attempt to identify and answer key questions about teaching as a scholarly act, including appropriate research methods, types of evidence for such scholarship, standards and criteria for peer review, elements unique to a discipline, and interdisciplinary connections.

Step 4) Seminar members will prepare articles and presentations on the seminar experience and their course research. The workshop leader will construct a seminar workbook as a model device for subsequent faculty development activity.

Occasions for sharing processes and products of campus work are part of the second phase of the Campus Program. Beginning with a colloquium prior to the 1999 American Association for Higher Education National Conference on Higher Education, two-day colloquia will be held each year to enable cross-campus interaction and reports of progress both by Pew Scholars and by Campus Program participants. Meetings of campuses of similar type or working on similar issues are being held as interest and need arise.

Campuses are supported in their work also by a WebCenter that of- 
fers resources, places to post drafts or finished products, sites of conversation around specific themes, and information about the work of all registered campuses and of individuals on those campuses. Faculty and staff on a Campus Program campus can sign on to make full use of all the features of the WebCenter.

\section{Work with Scholarly Societies}

Faculty members often derive their primary professional identify through their disciplines, reinforced by the current form of graduate education and by the ways in which their work is acclaimed. The third arena of activity in CASTL acknowledges the centrality of the disciplinary and professional societies in promoting the scholarship of teaching and learning. Some associations have actively and publicly supported the work. For example, the American Sociological Association has published a book on peer review in sociology, building on work done by sociologists and others in the AAHE Peer Review project. The American Historical Association is working with Pew Scholar William Cutler from Temple University in providing examples of course portfolios on the web for response and use by other historians. The National Council of Teachers of English, the Academy of Management, and the American Chemical Society are featuring the topic of the scholarship of teaching and learning at upcoming conferences. Pew Scholar Randy Bass is leading a major project for the American Studies Association focusing on the ways in which the web opens new opportunities for both creation of and interaction about scholarship of teaching and learning. These examples illustrate the ways in which scholarly societies can play a central role in fostering the scholarship of teaching and learning. At the 1999 Colloquium on Campus Conversations at AAHE, Carla Howery of the American Sociological Association challenged her colleagues who provide leadership in associations to do an association audit. In that audit, associations ask themselves how they contribute not only to the professional identity but also to the full range of professional work of their members, including the scholarship of teaching and learning. CASTL and AAHE have convened over 20 associations, primarily in disciplines represented in its Pew Scholar cohorts, to discuss strategies for supporting their members in this professional work and to devise their own projects for seed funding. The work of Pew Scholars like Jeff Chin and Donna Duffy offer essential information to associations about the impact of their work in this area. 


\section{What's NeXt?}

At the 1999 Pew Scholar Institute, Peter Alexander, a mathematician from Heritage College, sparked thinking with the application of some principles of architecture to the scholarship of teaching and learning. Peter described as essential to architectural projects commodity, firmness, and delight. Commodity implies utility: the structure must serve the purposes for which it is built. Firmness includes substantiality or significance. And delight brings pleasure, joy, and satisfaction into the equation. In a later session at that same Institute, Lee Shulman picked up that language in advocating for distributed awareness, practice, and valuing of the scholarship of teaching and learning. He suggested that the standard of value for the scholarship of teaching and learning would certainly include at least utility (commodity) and delight. How will we know if this scholarship has utility and delight? Shulman answers that the work will be useful and interesting to more and more people in higher education if it is 1) generative, 2) longitudinal, and 3) collaborative.

Shulman referred to Aristotle's distinction between a face and a bag of coins. If any part of a face is removed or added to, the face changes, becoming something essentially different. If, on the other hand, a bag of coins has a few coins removed or added, the bag is recognizable as the same bag of coins. Shulman hopes that the scholarship of teaching and learning will change the face of higher education, not just alter the same old bag.

To make this change, the scholarship must first be generative, demonstrating clearly why doing the work is worth the trouble, that is, demonstrating that it is worth changing habits of mind and processes of teaching and learning that have been deeply engrained and are deeply familiar.

Secondly, the view of scholarship of teaching and learning must be longitudinal. Just as pool players think of the next shot as one in a strategic series, we must see individual projects as part of efforts unfolding over time. Because new questions, occasions, and circumstances will evolve, new hypotheses, projects to test those hypotheses and ways to share conclusions will need to be developed. Along this line, Pew Scholar Randy Bass calls for a new way of viewing problems in teaching and learning, that is, as interesting and complex problems not to be solved once and for all but to be continuously explored as they emerge in different contexts (Bass, 1998).

Thirdly, the scholarship of teaching and learning is collaborative. Our rich tradition of building on the research of scholars before us or be- 
side us holds in the scholarship of teaching and learning. "It takes a village," said Shulman about the need for collaborative efforts in addressing the wonderfully complex problems that engage our intellectual and emotional abilities. This collaborative work will add to the critical mass that will serve as "an existence proof" for our colleagues who are just beginning to understand the nature of the scholarship of teaching and learning (Shulman, 1999).

In his book The Fifth Discipline, Peter Senge advises that transformative change can occur when genuine openness is present. He calls for "reflective openness," which "looks inward and starts with the willingness to challenge our own thinking, to recognize that any certainty we ever have is, at best, a hypothesis about the world. It involves not just examining our own ideas, but mutually examining others' thinking" (Senge, 1990). The Pew Scholars Fellowship Program, the Campus Program, and the work with scholarly societies efforts all embrace the need to challenge our own deepest thinking and to do so in the company of others engaged in the same work. Teaching and learning will become central in the definition of a professor's role, the identification of a campus's function, and the heart of disciplinary association existence only when we accept the challenge of exploring with commodity, firmness, and delight the complex and exciting sites of learning in higher education.

\section{REFERENCES}

Bass, R. (1998). Inventio. www.georgemason.com.

Cambridge, B. L. (2000). The scholarship of teaching and learning: A national initiative. In M. Kaplan \& D. Lieberman (Eds.), To improve the academy, 18, 55-68. Bolton, MA: Anker.

Glassick, C., Huber, M., \& Maeroff, G. (1997). Scholarship assessed: Evaluation of the professoriate. San Francisco, CA: Jossey-Bass.

Hutchings, P. (1999). 1999 Pew Scholars Institute. Menlo Park, CA.

Senge, P. (1990). The fifth discipline. London: Century, Business.

Shulman, L. (1999). 1999 Pew Scholars Institute. Menlo Park, CA. 


\section{Contact:}

Barbara L. Cambridge

American Association for Higher Education

One Dupont Circle, Suite 360

Washington, DC 20036

(202) 293-6440

Email: bcambridge@aahe.org

Barbara L. Cambridge is director of teaching initiatives at the American Association for Higher Education. She is on leave from Indiana University Purdue University, Indianapolis where she is professor of English and associate dean of the faculties. At AAHE, Cambridge coordinates the Campus Program, one of the three activities of the higher education program at the Carnegie Foundation for the Advancement of Teaching.

\section{An Invitation}

\section{Videotape}

A videotape titled Fostering a Scholarship of Teaching is now available to introduce key concepts behind the Pew Scholars Fellowship Program and the Campus Program. The video, which features, among others, Lee Shulman and selected Pew Scholars, can be used effectively to help groups of faculty understand the concept of the scholarship of teaching and learning, prompt consideration of involvement in the Campus Program, and explain CASTL to educational leaders and others interested in the quality of education.

Any campus registered for the Campus Program is welcome to a copy of the video by contacting Teresa Antonucci at American Association for Higher Education. She may be reached at tantonucci@aahe.org or (202) 293-6440.

Anyone else interested in the video may order a copy by contacting Terri Coats in the publications department of the Carnegie Foundation for Teaching at (650) 566-5102. The cost for the video is $\$ 9.00$, including shipping with sales tax if applicable.

\section{Booklets}

Booklets about the Campus Program and about the Pew Scholars Fellowship Program are available from AAHE and from the Carnegie Foundation. Contact either site for single or multiple copies. 